\title{
Assessing the benefits of PV var absorption on the hosting capacity of LV feeders
}

DOI:

10.1109/ISGTEurope.2013.6695423

Link to publication record in Manchester Research Explorer

\section{Citation for published version (APA):}

Ballanti, A., Pilo, F., Navarro-Espinosa, A., \& Ochoa, L. F. (2013). Assessing the benefits of PV var absorption on the hosting capacity of LV feeders. In 2013 4th IEEE/PES Innovative Smart Grid Technologies Europe, ISGT Europe 2013/IEEE/PES Innovative Smart Grid Technol. Europe, ISGT Europe https://doi.org/10.1109/ISGTEurope.2013.6695423

\section{Published in:}

2013 4th IEEE/PES Innovative Smart Grid Technologies Europe, ISGT Europe 2013|IEEE/PES Innovative Smart Grid Technol. Europe, ISGT Europe

\section{Citing this paper}

Please note that where the full-text provided on Manchester Research Explorer is the Author Accepted Manuscript or Proof version this may differ from the final Published version. If citing, it is advised that you check and use the publisher's definitive version.

\section{General rights}

Copyright and moral rights for the publications made accessible in the Research Explorer are retained by the authors and/or other copyright owners and it is a condition of accessing publications that users recognise and abide by the legal requirements associated with these rights.

\section{Takedown policy}

If you believe that this document breaches copyright please refer to the University of Manchester's Takedown Procedures [http://man.ac.uk/04Y6Bo] or contact uml.scholarlycommunications@manchester.ac.uk providing relevant details, so we can investigate your claim.

\section{OPEN ACCESS}




\section{Assessing the Benefits of PV Var Absorption on the Hosting Capacity of LV Feeders}

\author{
Andrea Ballanti \\ Fabrizio Pilo \\ Department of Electrical and Electronic Engineering \\ University of Cagliari \\ Cagliari, Italy \\ andrea_ballanti@libero.it \\ pilo@diee.unica.it
}

\author{
Alejandro Navarro-Espinosa \\ Luis F. Ochoa \\ School of Electrical and Electronic Engineering \\ The University of Manchester \\ Manchester, UK \\ alejandro.navarroespinosa@manchester.ac.uk \\ luis_ochoa@ieee.org
}

\begin{abstract}
The UK has reached, thanks to the Feed-In-Tariff scheme, an installed photovoltaic (PV) capacity of almost $1.5 \mathrm{GW}$ mostly connected to low voltage $(\mathrm{LV})$ networks. Voltage rise issues have started to appear particularly in clusters of PV systems. Thus, in order to defer potential network reinforcements, Distribution Network Operators have to consider alternative solutions that can cost-effectively allow hosting the ongoing and future uptake of PV systems. Adopting a thorough Monte Carlo-based analysis, this work evaluates the potential benefits from using the power factor capabilities of PV systems connected to $L V$ feeders. The results, based on a real UK suburban $L V$ feeder, show that for a given penetration level, the number of customers affected by voltage issues at a given penetration level can be significantly reduced when adopting PV reactive power absorption. However, this strategy had a limited effect on the reduction of the overall voltage rise issue.
\end{abstract}

Index Terms-- Low voltage networks, small scale PV, Monte Carlo, reactive power absorption.

\section{INTRODUCTION}

In the last few years, the installed photovoltaic (PV) capacity in the UK has grown from almost zero to $1.5 \mathrm{GW}$ [1] thanks to the Feed-In-Tariff scheme. Installations are mainly domestic (single phase) ranging from 3 to $4 \mathrm{kWp}$. Although the PV installed capacity is only a fraction of the national peak demand, issues in low voltage (LV) networks have started to appear particularly in clusters of PV systems (e.g., housing associations). One of these problems is the voltage rise given that in the UK high PV generation is coincident with, typically, low levels of demand. Indeed, voltage rise can significantly limit the hosting capacity of LV networks [2]-[3].

In the UK, as in other countries, PV installations have to be capable of operating within a power factor range $(0.95$ inductive/capacitive [4]). However, DNOs do not typically request any specific settings resulting in PV installations adopting unity power factor. This readily available reactive power absorption capability could represent an opportunity to counteract the voltage rise due to reverse power flows.
Some recent studies have dealt with different aspects when assessing the hosting capacity of LV networks. In [5] the cost effectiveness and technical impacts of several reactive power supply methods for $\mathrm{PV}$ units like $\mathrm{Q}(\mathrm{U})$ and $\mathrm{Q}(\mathrm{P})$ were investigated considering a real suburban network. However, only the worst case scenario (no load-max generation), fixed PV locations and equal PV size were adopted to evaluate the hosting capacity. The load and PV power profile uncertainties were taken account of in [6] to assess the impacts of $\mathrm{PV}$ and micro combined heat and power ( $\mu \mathrm{CHP}$ ) technologies. It is worth noting that a specific PV unit size was considered. In [7] four real feeders have been object of a PV impact study. The PVs have been located in several different locations (beginning, end, random and all in one phase). In [8] both statistic and deterministic approaches are proposed. However, these were applied to evaluate the wind power hosting capacity of MV networks adopting the voltage of the $\mathrm{LV}$ end-users as a metric.

Deterministic methods using simplified or synthetic feeders, average load profiles and based on the worst case scenario are usually adopted by DNOs. However, when evaluating the impacts of low carbon technologies, the unpredictability of size, position and production profiles is an aspect that must be considered. This is also the case when modeling residential loads. In addition, while test networks are very useful in carrying out impact studies, they cannot capture the particular feature of real LV networks (e.g., unbalanced load connections, cable types, etc.). Finally, it is crucial to assess the corresponding effect considering metrics used by DNOs, such as voltage compliance with the standard EN 50160.

This study proposes a Monte Carlo-based approach applied to a real UK LV network considering all the above discussed uncertainties. The hosting capacity is evaluated considering the probability of occurrence of overvoltage at customer level according to different PV power factors. 


\section{Accepted Paper}

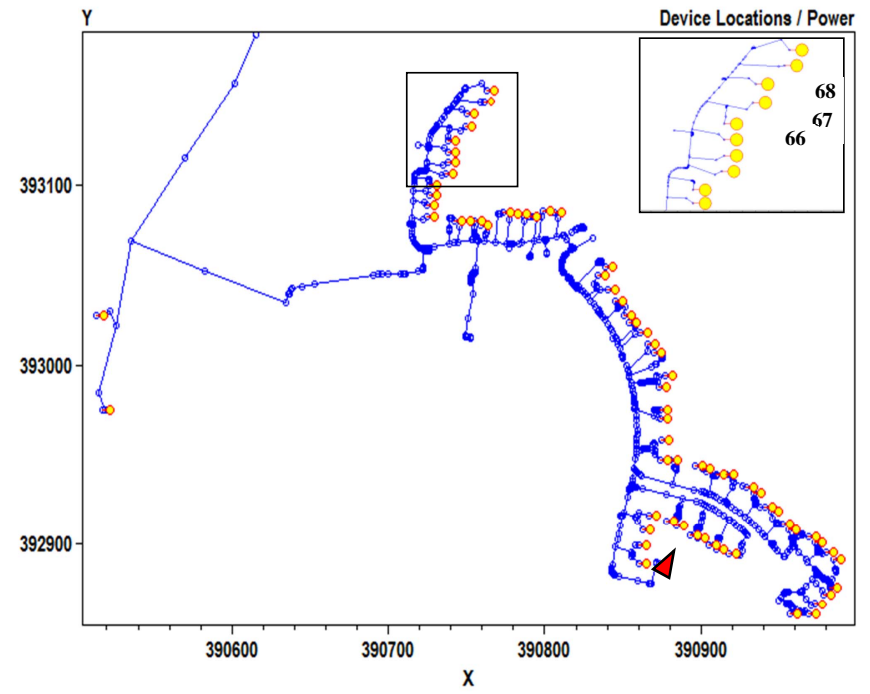

Fig. 1. Feeder with 70 customers (yellow circles) and distribution transformer (red triangle).

TABLE I R/X DISTRIBUTION RELATIVE TO THE TOTAL LENGTH OF THE FEEDER

\begin{tabular}{c|c|c|c|c}
\hline $\mathbf{R} / \mathbf{X}$ & $0.5-1.5$ & $3-7$ & $7-15$ & $>15$ \\
\hline $\boldsymbol{\%}$ & 6 & 48 & 42 & 4 \\
\hline
\end{tabular}

This paper is structured as follow: Section II describes the network under study and the adopted load and PV profiles. In Section III the proposed method is explained. Thereafter in Section IV the hosting capacity is evaluated considering PV installations absorbing reactive power. Finally the conclusions are drawn in Section V.

\section{FEEDER, LOAD AND PV MODELLING}

\section{A. Real UK LV network}

The feeder under study, shown in Fig. 1, is part of an LV underground network located in the North West of England. This is a $400 \mathrm{~V}$ three-phase feeder with neutral where each customer is single-phase connected. The total cable length is $2272 \mathrm{~m}$ and the average $\mathrm{R} / \mathrm{X}$ ratio is 10.1 with a distribution detailed in Table I. Each customer is defined by a consecutive number from 1 to 70 as illustrated in Fig. 1 for a few points.

\section{B. Feeder}

As previous studies have highlighted (e.g., [6], [7], [9]), a four wire modelization is necessary in order to deal with unbalances that characterize real LV networks. Hence a $4 \times 4$ impedance matrix representation has been adopted for each line since zero and positive impedances as well as geometric cable features were available. Several neutral to ground connections (aka protective multiple earth) have been considered along the feeder consistently to UK practices. In addition, the resistance for neutral to ground connections at homes (through water pipes or other conductive elements) has been estimated. In [10] is highlighted that if the effects of neutral wire are neglected the solution of voltages and currents will be incorrect. Moreover, the corresponding ground current obtained in the model is corroborated by real field measurements.

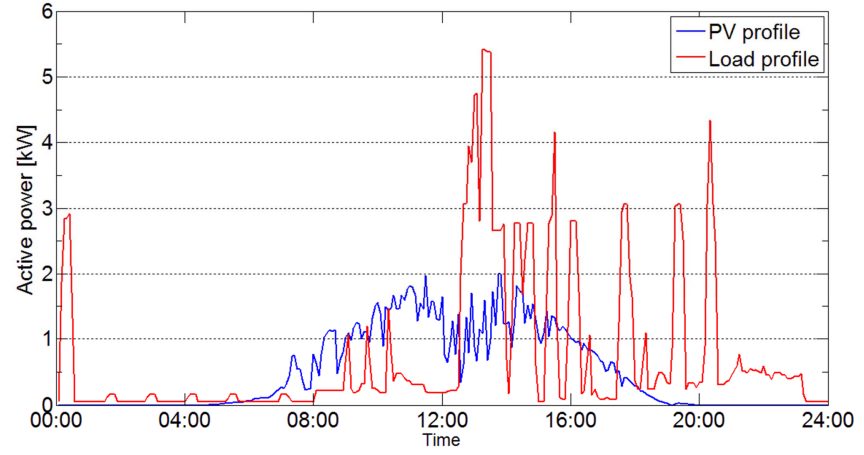

Fig. 2 Example of adopted load and PV profile, 10min average

\section{Load Profiles}

Each load profile has been produced by a stochastic modeling tool [11] (CREST tool) that realistically simulates the residential demand. A pool of 1000 summer daily profiles has been generated. The number of people in each house is consistent with the UK statistics [12]. Finally, the power factor has been considered equal to 0.95 and constant all the time.

\section{PV profiles}

In order to increase the confidence on the results, real irradiance data has been adopted. In particular, a pool of 88 daily irradiance profiles ranging from June to August has been used. A realistic proportion of cloudy and sunny UK days is considered. Moreover, the optimal tilt and azimuth have been assumed. An overall efficiency of inverter and cable of $95 \%$ has been adopted. The spread of PV sizes follows UK national statistics [1].

It is important to highlight that in this work PV penetration (PV\%) is expressed as percentage of customers with a PV installation. An example of a domestic load (4 people) and a PV profile ( $2 \mathrm{kWp})$ is shown in Fig. 2 .

\section{METHODOLOGY}

To determine how PV reactive power absorption impacts on the hosting capacity of an LV feeder, it is necessary to assess:

- Different PV power factors (PFs). Aligned with the UK requirements [3], it will be considered $0.95,0.975$ (both absorbing var) and unity power factors.

- Different PV penetration levels (PV\%). A range from $0 \%$ to $100 \%$ (with $10 \%$ steps) will be considered here.

The combination of the above as well as other aspects such as the location of PV installations and load characteristics, create a myriad of scenarios. Consequently, to evaluate a representative sample of all possible scenarios a Monte Carlo approach will be adopted [2]-[3].

To determine the technical characteristics for each scenario, four 'input variables' for the Monte Carlo technique have been defined. They are presented in Table II. 


\section{Accepted Paper}

TABLE II. 'INPUT VARIABLES’ FOR EACH PV\%-PF SET OF SCENARIOS

\begin{tabular}{c|ccc}
\hline Input Variable & Set size & Input domain & Criteria \\
\hline $\begin{array}{c}\text { Set of PV } \\
\text { sizes }\end{array}$ & $\begin{array}{c}70 \times \text { no. } \\
\text { of PV\% }\end{array}$ & $\begin{array}{c}\text { From } 0.5 \text { to } \\
4 \mathrm{kWp}\end{array}$ & $\begin{array}{c}\text { Random, consistent } \\
\text { with UK statistics [1] }\end{array}$ \\
\hline $\begin{array}{c}\text { Set of } \\
\text { irradiance } \\
\text { profiles }\end{array}$ & 1 & $\begin{array}{c}\text { Pool of } 88 \text { real } \\
\text { profiles }\end{array}$ & Uniform random \\
\hline $\begin{array}{c}\text { Set of PV } \\
\text { locations }\end{array}$ & $\begin{array}{c}70 \times \text { no. } \\
\text { of PV\% }\end{array}$ & $\begin{array}{c}\text { Among the } 70 \\
\text { customers }\end{array}$ & Uniform random \\
\hline $\begin{array}{c}\text { Set of load } \\
\text { profiles }\end{array}$ & 70 & $\begin{array}{c}\text { Pool of } 1000 \\
\text { CREST profiles }\end{array}$ & Uniform random \\
\hline
\end{tabular}

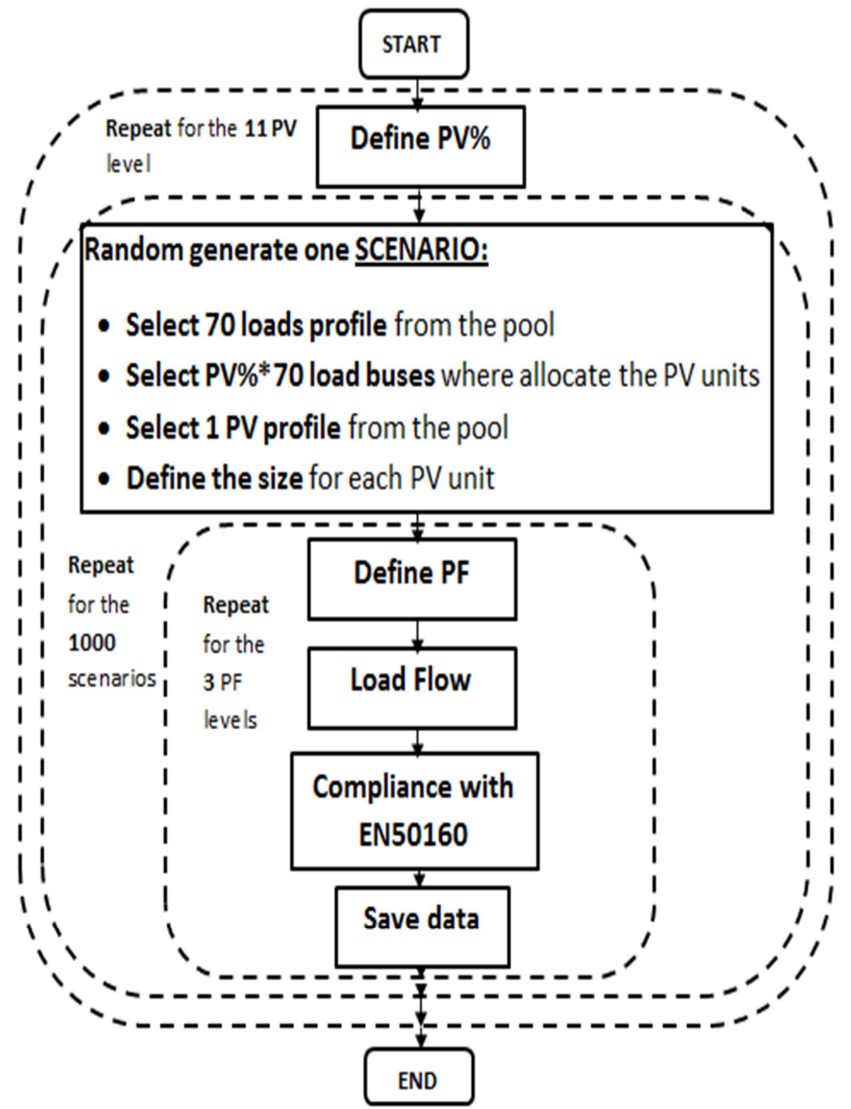

Fig. 3. Monte-Carlo adopted approach

The sample to be studied in this work consists of 1000 scenarios per PV\%-PV combination. The results will be representative of the whole (unknown) population thanks to a random choice of possible input variables within a "realistic" domain as defined Table II. The occurrence of voltage issues (and any other technical parameter) can then be quantified on a statistical basis after analyzing each of these 1000 scenarios. The procedure carried out is summarized in Fig.3.

In terms of the power flow analysis, OpenDSS [13] was used given its ability to model unbalanced networks and run time series power flows.

Finally, the impact on voltages is assessed considering the standard EN50160. This standard (adapted for UK LV networks) states that the 10 minute rms phase to neutral voltages should not exceed $10 \%$ of nominal (230V). Although the standard considers a week, here it will be used for a day.

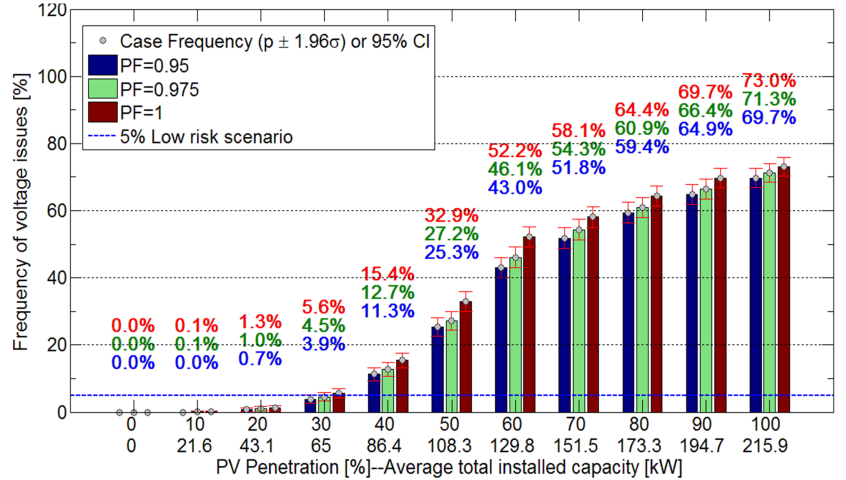

Fig. 4 Histogram of voltage issues for different PV\% and PF

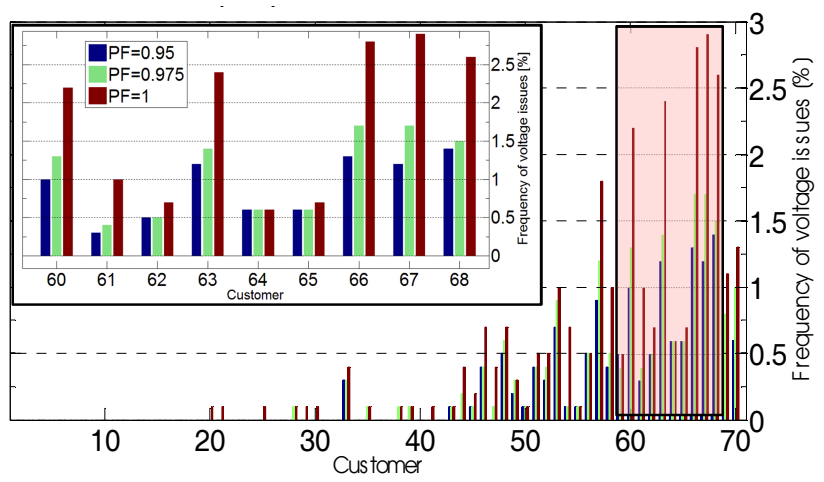

Fig. 5 Frequency of voltage issues per customer for PV $\%=30 \%$.

\section{RESULTS}

\section{A. Overall Analysis}

The 'risk' associated with the hosting capacity for each $\mathrm{PV} \%$-PF set of scenarios is considered here as the frequency whereby a voltage problem appears. This is shown in Fig.4.

For instance, with a penetration level of $20 \%$ (or $43.1 \mathrm{kWp}$ of total average installed PV capacity) and $\mathrm{PF}=0.95$, voltage problems will be experienced in $0.7 \%$ of the corresponding 1000 scenarios. For this case, the potential 'risk' might be considered very low by the DNO and hence connection requests up to that level (14 customers) could proceed quickly (even with unity power factor).

The 95\% confidence interval (CI) is defined by the standard deviation $\sigma$ and the average $\mu$ both of them derived by applying the Central Limit Theorem [14]. The results reinforce the expected positive correlation between a $\mathrm{PF}$ absorbing reactive power and the voltage rise problem.

For penetration levels up to $30 \%$ the relative benefit is significant (about 50\% reduction in some cases) because the voltage limits have been exceeded by only tenths of volts in many scenarios with $\mathrm{PF}=1$. In this case the absorption of var will be strong enough to bring voltages within the limits with $\mathrm{PF}=0.95$.

Assuming that the DNO can only accept a 'low risk' of $5 \%$ (i.e., voltage issues occurring in 5\% of the corresponding 1000 scenarios), then the maximum hosting capacity for the studied LV feeder is $30 \%$ (or 21 customers with a total average installed PV capacity of $65 \mathrm{kWp}$ ). 


\section{Accepted Paper}

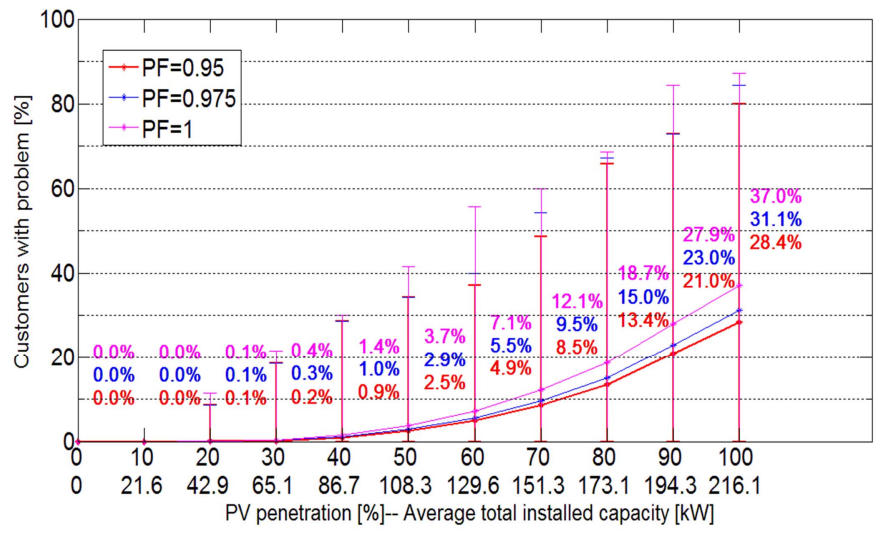

Fig. 6 Min-mean-max percentages of customers with problems

For this penetration, although the PV absorption of reactive power brings benefits (the risk can be limited to $3.9 \%$ ), unity power factor is still adequate.

Beyond 30\% voltage issues become much more frequent and sharply increase for higher PV penetrations. At the same time, the relative benefit of PV reactive power absorption reduces with more PV installations. Indeed, while for a penetration of $40 \%$ the 'risk' is cut a third when adopting $\mathrm{PF}=0.95$, this becomes a tiny fraction for penetrations exceeding $60 \%$. This highlights the fact that although the PV absorption of reactive power does bring benefits, they might not be that significant when they are needed the most, i.e., at high penetrations.

\section{B. Analysis per Customer}

A much closer look at the location of the voltage issues can reveal other aspects when assessing the hosting capacity of LV feeders. Fig.5 presents the frequency of voltage issues per customer for a PV penetration of $30 \%$.

From this figure, it is clear that customers 66,67 and 68 are the 'bottleneck' in terms of hosting capacity as they experience the highest frequency of voltage issues. This is mainly because of their relative geographical position in the feeder (the end of a corridor, see Fig.1). It can also be seen the extent to which a $\mathrm{PF}=0.95$ benefits individual customers, reducing the frequency of voltage issues to less than $1.5 \%$. In addition, it is worth noting that the highest frequency of voltage issues for a single customer (almost 3\%, customer 67) is less than the frequency for the feeder as a whole (5.6\%, Fig.5). This means that no customer experiences voltage issues for all the problematic scenarios summarized in Fig.5.

The number of customers with problems in each PV\%-PF set of scenarios is summarized in Fig. 6. For a PV penetration of $30 \%$, an average of 0.07 customers (i.e., $0.1 \%$ ) could experience problems. With $80 \%$ of customers with PV installations and $\mathrm{PF}=0.95$, only less than a tenth might be affected by voltage issues in average. However, as shown in Fig. 5, this is very likely to happen $(59.4 \%$ of the simulated scenarios).

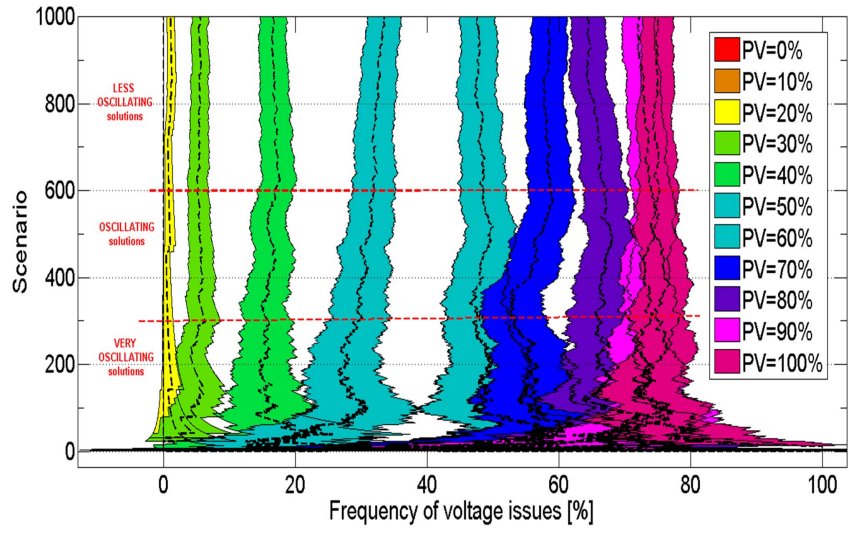

Fig. 7 Cases frequency (dashed lines) and 95\% CI (colour areas) evolution throughout each scenario with $\mathrm{PF}=1$

TABLE III AVEREAGE FREQUENCY OF VOLTAGE ISSUES OBTAINED BY DIFFERENT MONTE CARLO (MC) SIMULATIONS (1000 SCENARIOS EACH)

\begin{tabular}{c|c|cccccc}
\multicolumn{2}{c|}{} & \multicolumn{7}{|c}{ PV Penetration [\%] } \\
\hline$P F$ & MC & $\mathbf{1 0}$ & $\mathbf{3 0}$ & $\mathbf{5 0}$ & $\mathbf{7 0}$ & $\mathbf{9 0}$ & $\mathbf{1 0 0}$ \\
\hline \multirow{3}{*}{0.95} & $\mathbf{1}$ & 0 & 2.9 & 23.8 & 50.4 & 66.6 & 70.8 \\
& $\mathbf{2}$ & 0 & 3.9 & 25.3 & 51.8 & 64.9 & 69.7 \\
& $\mathbf{3}$ & 0 & 3.7 & 26.0 & 53.0 & 67.2 & 69.3 \\
\hline \multirow{3}{*}{0.975} & $\mathbf{1}$ & 0 & 3.4 & 26.5 & 53.6 & 68.4 & 77.1 \\
& $\mathbf{2}$ & 0.1 & 4.5 & 27.2 & 54.3 & 66.4 & 71.3 \\
& $\mathbf{3}$ & 0 & 4.4 & 28.1 & 55.4 & 68.6 & 70.3 \\
\hline \multirow{3}{*}{1} & $\mathbf{1}$ & 0 & 5.1 & 32.3 & 57.9 & 71.6 & 74.8 \\
& $\mathbf{2}$ & 0.1 & 5.6 & 32.9 & 58.1 & 69.7 & 73.0 \\
& $\mathbf{3}$ & 0 & 5.8 & 34.4 & 59.6 & 71.5 & 73.0
\end{tabular}

It can also be observed that there is a positive correlation between voltage problems and reactive power absorption. It decreases the average number of customers affected from $50 \%(\mathrm{PV} \%=40 \%)$ to $24 \%(\mathrm{PV} \%=100 \%)$ when the $\mathrm{PF}$ is set from 1 to 0.95 (absorbing var). This means that, although the reactive power absorption might not avoid the occurrence of voltage issues for the feeder as a whole, it is a strategy that could reduce the number of customers affected by it.

\section{V.DISCUSSION}

\section{A. Modeling Aspects}

It is important to stress that the assessment of the hosting capacity of LV feeders is as good as the technical considerations taken.

For the studied feeder, the following aspects have a significant impact on the results:

- High PV generation and low demand that characterizes a typical residential feeder in the UK summer period;

- Several customers are relatively far from the substation;

- PV reactive power absorption was modeled solely based on the power factor (no P-Q capability curve);

- Phase-to-ground busbar voltage was set to constant $240 \mathrm{~V}$ (1.04 p.u); and, 


\section{Accepted Paper}

- Protective multiple earth (PME) connections were modeled.

In practice, LV busbars can be considered to provide constant values of voltages (although this depends on the characteristics of the upstream network). However, the actual voltage magnitude (i.e., off load tap settings) becomes an important parameter that can significantly affect the hosting capacity [3].

Phase connections of customers were relatively balanced (20-24-26 customers in phase A-B-C, respectively) albeit currents through the neutral, sometimes even higher than phase currents, were found (which is consistent with what happens in practice).The ground connections along the feeder and at house level (i.e., PME) led to a positive effect in reducing the neutral voltage. However, it is difficult to quantify the effects of this detailed modeling on the whole analysis.

\section{B. Monte Carlo Simulations}

The number of adopted scenarios per PV\%-PF combination is a key aspect for the success of a Monte-Carlo based approach. A low number could lead to false results. On the other hand, too many scenarios could require unnecessary computational resources and time. For instance, considering the studied LV feeder, 500 to 600 scenarios could give only 'oscillating' solutions as clearly shown in Fig.7.

However, the stability of one solution does not imply its reliability. In other words it could be stable but converge to a value not representative of the whole population. To illustrate this, three Monte Carlo simulations have been run for different PV\%-PF cases (Table III).

The average frequencies of voltage issues are quite close to each other; very often within one standard deviation. Given that it is unlikely that three independent Monte Carlo runs produce almost the same wrong solutions, the stability and reliability of 1000 scenarios is considered to be robust.

\section{CONCLUSION}

A Monte Carlo-based approach was adopted to investigate the benefits of $\mathrm{PV}$ reactive power absorption on the hosting capacity of LV feeders.

The results, based on a real UK suburban LV feeder, show that when looking at the performance of the feeder, the PV absorption of reactive power does help improving voltages (i.e., reducing voltage excursions). However, the improvements are very limited and even less during high penetration levels - when is needed the most.

Nonetheless, although the reactive power absorption might not avoid the occurrence of voltage issues for the feeder as a whole, the results clearly demonstrated that this strategy could reduce the number of customers affected by it.
Consequently, where small-scale PV connections are by regulation requested to have the capability to absorb reactive power (as is the case in the UK), then this should be considered as a zero-cost opportunity to help tackling voltage rise issues.

\section{ACKNOWLEDGMENT}

The studied LV feeder has been made available by Electricity North West Limited (ENWL), UK. The authors would like to thank the Centre for Renewable Energy Systems Technology at Loughborough University, UK, and the Whitworth Meteorological Observatory, UK for making available the CREST tool and real irradiance data, respectively.

\section{REFERENCES}

[1] UK DECC "Weekly solar PV installation and capacity based on registration date”, March 2013, , [Online].Available https://www.gov.uk/government/statistical-data-sets/weekly-solar-pvinstallation-and-capacity-based-on-registration-date

[2] A. Navarro, Luis F. Ochoa, D. Randles "Monte Carlo-Based Assessment of PV Impacts on Real UK Low Voltage Networks", IEEE PES GM 2013

[3] A. Navarro, L.F. Ochoa, P. Mancarella, D. Randles. "Impacts of photovoltaics on low voltage networks: A case study for the North West of England". 22nd International Conference on Electricity Distribution CIRED 2013. 2013: 1-4.

[4] Energy Networks Association, Engineering Recommendation G83 Issue 2 "Recommendations for the Connection of Type Tested Smallscale Embedded Generators (Up to 16A per Phase) in Parallel with Low-Voltage Distribution Systems", 2012

[5] T. Stetz, F. Marten, M. Braun "Improved Low Voltage Grid-Integration of Photovoltaic Systems in Germany". IEEE Transactions on Sustainable Energy, 4(2), 534-54, 2013

[6] Murray Thomson, David G. Infield, "Network Power-Flow Analysis for a High Penetration of Distributed Generation", IEEE Transactions on power systems, vol 22, No 3,Auguts 2007

[7] C. Gonzalez, J. Geuns, S. Weckx, T. Wijnhoven, P. Vingerhoets, T. De Rybel, J. Driesen, "LV Distribution Network Feeders in Belgium and Power Quality Issues due to Increasing PV Penetration Levels", 2012 3rd IEEE PES Innovative Smart Grid Technologies Europe (ISGT Europe), Berlin

[8] M. Bollen "Overvoltages due to Wind Power Hosting Capacity, Deterministic and Statistical approaches", 2008 Electrical Power Quality \& Utilization Magazine, vol 3 issue 2

[9] A. Collinson, "The impact of high penetration levels on electrical distribution networks", UMIST, Tech. Rep. Nov. 2002

[10] T.H. Chen, W. Yang, "Analysis of Multi-Grounded Four-Wire Distribution Systems Considering the Neutral Grounding", IEEE Transaction on power delivery, vol 16, No 4, Octover 2001

[11] I. Richardson and M. Thomson, "Domestic Electricity Demand ModelIntegrated Domestic Electricity Demand and PV Micro- generation Model," Loughborough University Institutional Repository, [Online]. Available http://hdl.handle.net/2134/7773, 2010.

[12] Office for National Statistics, "Families and households, 2001 to 2011," Statistical Bulletin, January 2012.

[13] EPRI, "Open Distribution System Simulator [Online]," Available http://sourceforge.net/apps/mediawiki/electricdss

[14] A. M. Johansen, L. Evers" Monte Carlo Methods", University of Bristol, Department of Mathematics 